\title{
Do leatherback turtles Dermochelys coriacea forage during the breeding season? A combination of data-logging devices provide new insights
}

\author{
Andrew E. Myers*, Graeme C. Hays \\ Department of Biological Sciences, Institute of Environmental Sustainability, University of Wales, Swansea SA2 8PP, UK
}

\begin{abstract}
Animals which undertake migrations from foraging grounds to suitable breeding areas must adopt strategies in these new conditions in order to minimise the rate at which body condition deteriorates (which will occur due to oogenesis or provisioning for young). For some animals this involves continuing foraging, whereas for others the optimal strategy is to fast during the breeding season. The leatherback turtle undertakes long-distance migrations from temperate zones to tropical breeding areas, and in some of these areas it has been shown to exhibit diving behaviour indicative of foraging. We used conventional time-depth recorders and a single novel mouth-opening sensor to investigate the foraging behaviour of leatherback turtles in the southern Caribbean. Diving behaviour suggested attempted foraging on vertically migrating prey with significantly more diving to a more consistent depth occurring during the night. No obvious prey manipulation was detected by the mouth sensor, but rhythmic mouth opening did occur during specific phases of dives, suggesting that the turtle was relying on gustatory cues to sense its immediate environment. Patterns of diving in conjunction with these mouth-opening activities imply that leatherbacks are attempting to forage during the breeding season and that gustatory cues are important to leatherbacks.
\end{abstract}

KEY WORDS: Leatherback $\cdot$ Turtle $\cdot$ Diving $\cdot$ Foraging $\cdot$ Seal $\cdot$ Penguin $\cdot$ Data logger

\section{INTRODUCTION}

Many animals engage in seasonal long-distance migrations between specific breeding and foraging areas. Examples of this are well known among birds (e.g. Adelie penguins; Davis et al. 1996), mammals (e.g. seals, whales; Brillinger \& Stewart 1998, Laidre et al. 2003) and reptiles (e.g. green turtle; Godley et al. 2002). When breeding sites are selected on the basis of their suitability for breeding rather than foraging, animals must adapt their behaviour to maximise their reproductive output. During the breeding season, a fast-forage continuum exists for the animals, with some directing their efforts solely to reproduction and not attempting to forage. This is the case, for example, in female elephant seals Mirounga leonina, which stay ashore while rearing and nursing pups, surviving for several weeks on fat reserves (Fedak et al. 1996). At the other end of the fast-forage continuum are species which continually attempt to feed during the breeding season, for example, returning between foraging trips to provision young (e.g. penguins; Chappell et al. 1993; fur seals; Arnould \& Hindell 2001). This same fastforage continuum observed in breeding mammals and birds is also found in the only group of marine reptiles that exhibit long-distance migration: sea turtles. For example, at some sites where food is unavailable, female green turtles are thought to spend much of the time between consecutive nesting events (the internesting interval) in a largely quiescent state in nearshore waters (Hays et al. 2000a). In contrast, at breeding sites such as northern Cyprus, where seagrass beds are present, green turtles successfully forage (Hays et al. 2002). This fast-forage dichotomy in different populations of green turtle is reflected in different patterns of diving, including depth utilisation and dive dura- 
tions (Bjorndal 1980, Ogden et al. 1983, Hays et al. 1999, 2000a,b).

For the largest extant species of marine turtle, the leatherback Dermochelys coriacea, patterns of behaviour during the breeding season may likewise reflect the availability of food. Leatherbacks specialise in feeding on gelatinous zooplankton such as scyphozoan jellyfish and pyrosomes (Davenport 1998). There is limited evidence that leatherbacks might forage at some breeding sites. For example, female turtles nesting on the island of St. Croix in the northern Caribbean have shown little weight loss over the breeding season (Eckert et al. 1989), suggesting that foraging is occurring between nesting events. Leatherbacks from this rookery also exhibited diel periodicity in their diving behaviour, with more diving taking place at night, suggesting that these turtles are attempting to forage on vertically migrating zooplankton. However, how leatherbacks locate their jelly prey during these nocturnal dives remains unknown.

Here we investigate the internesting diving behaviour of leatherback turtles in the southern Caribbean. By examining the patterns of diving and depthduration relationships, we infer whether turtles were attempting to forage. Further, by deploying a novel 'mouth-opening sensor', we consider how and when leatherbacks might locate prey.

\section{MATERIALS AND METHODS}

A total of 17 turtles were selected from a nesting population at Levera Beach, Grenada, West Indies $\left(12.1^{\circ} \mathrm{N}, 61.7^{\circ} \mathrm{W}\right)$, to carry devices. An animal was selected if (1) flipper tags had been applied on a previous nesting attempt; (2) all or most previous nesting events had been observed at Levera Beach; and (3) migration would not be expected to commence immediately after the nesting event. All of these criteria decreased the likelihood of the animal not being sighted again due to either poor site fidelity, tag (and hence device) loss or the onset of migration at the end of the nesting season.

Grenada is an ideal location for studies examining the diving behaviour of leatherbacks as a steep slope close to the shore (Fig. 1) permits the full range of diving of an animal capable of diving to depths greater than $1000 \mathrm{~m}$, whereas turtles nesting on other major nesting beaches in the region (e.g. French Guiana, Suriname) are restricted by the relatively shallow Guyana shield extending $150 \mathrm{~km}$ from shore.

Time-depth recorders (TDR; DST Milli, Star Oddi) were attached to all 17 turtles. On 11 of these turtles the TDR was attached by nylon cable ties and wire to a rear flipper tag (monel), which were applied to the tur-

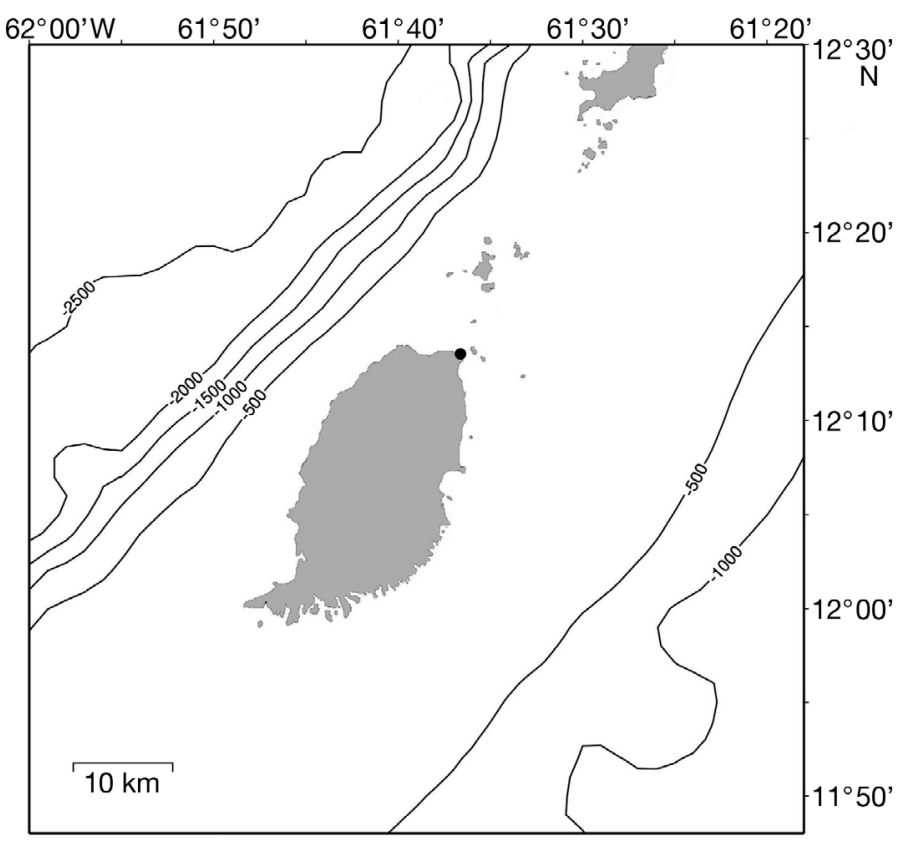

Fig. 1. Grenada and the surrounding area; bathymetry given in $500 \mathrm{~m}$ increments. Deep water $(>1000 \mathrm{~m})$ within a few $\mathrm{km}$ of the nesting site permits leatherbacks to dive to their maximum recorded depth, demonstrating the suitability of

Grenada for deployment (site indicated by black circle)

tles as part of an ongoing population study by volunteers from Ocean Spirits Inc., a Grenadian NGO.

The other 6 turtles were equipped with both a TDR and an IMASEN (Inter-Mandibular Angle Sensor), which were attached by a specially designed harness (Fig. 2). The harness consists of a canvas loop around the rear section of the animal connected to a padded aluminium base plate, which rests either side of the central keel on the carapace, and to a figure-of-eight ring on the plastron by bungee cord secured with nylon cable ties. The shoulder straps consist of bungee cord covered with rubber tubing to minimise abrasion. The TDR is attached to the base plate using cable ties and wire, with the main unit of the IMASEN being attached to the bungee cord inside the shoulder strap with an adjustable metal clip and nylon cable ties.

The IMASEN consists of a single-channel data logger joined to a Hall sensor by a $40 \mathrm{~cm}$ cable. The Hall sensor measured the potential difference across a thin sheet of metal which is dependent on the proximity and strength of a neodymium boron magnet. The magnet and Hall sensor were set in epoxy and glued to the lower and upper jaws, respectively, with cyanoacrylite glue (Fig. 3).

To calculate an approximation of the extent of the gape, it was assumed that the jaws form a straight line from the rictus (corner of the mouth) to the end of the 
beak (50 and $145 \mathrm{~mm}$ away from the sensor/magnet, respectively); simple trigonometry was used to estimate the actual gape for each reading in $\mathrm{mm}$ at the tip. Mouth-opening activity was considered for analysis if the gape exceeded $20 \mathrm{~mm}$. This threshold was chosen as it allowed the isolation of subtle mouth openings without detecting background noise (a $20 \mathrm{~mm}$ gape at the tip corresponds to a gape of approximately $2 \mathrm{~mm}$ at the sensor).

The gape measurements stated herein are likely to be subject to systematic inaccuracies, but they are consistently precise throughout the results. In spite of the approximations and assumptions used in the calculations, we believe that the resulting data are realistic and are representative of the actual mouth-opening gape.

The IMASEN unit measures $65 \times 35 \times 15 \mathrm{~mm}$ and weighs $25 \mathrm{~g}$ in air, with a resolution of 16 bits and a memory of $8 \mathrm{Mb}$. A sampling interval of $10 \mathrm{~Hz}$ was chosen as an appropriate trade-off between longevity (providing $4.6 \mathrm{~d}$ of data) and resolution. The TDR (38.4 $\times 12.5 \mathrm{~mm}, 9.2 \mathrm{~g}$ in air) attached in conjunction with the mouth sensor was programmed with a sampling interval of $10 \mathrm{~s}$, with all other TDRs using an interval of 1 min. With a capacity to record 21738 measurements of depth and temperature, these sampling intervals allowed us to record for durations of approximately 2.5 and $15 \mathrm{~d}$, respectively. On recovery, dives were manually coded to facilitate further analysis. For the purpose of this study a dive threshold of $10 \mathrm{~m}$ was selected, with consecutive readings shallower than $10 \mathrm{~m}$ being excluded from further analysis. By selecting this depth as a criterion for dives, short, shallow water movements, such as may occur during periods of sub-sur-

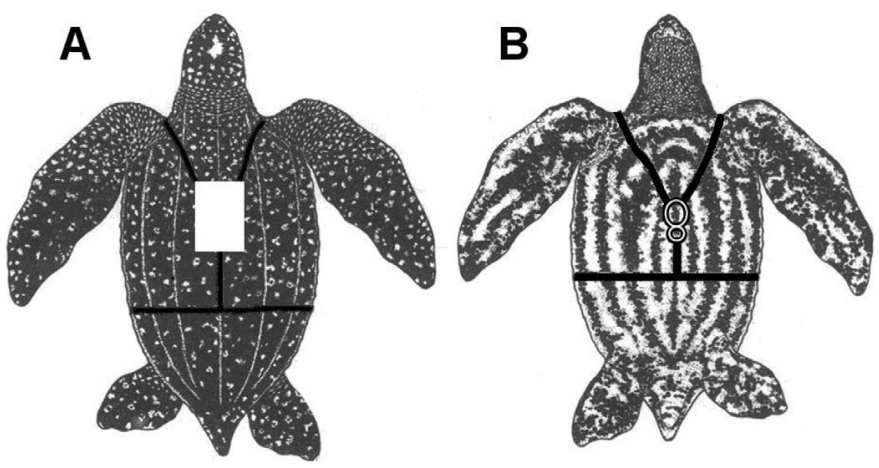

Fig. 2. Dermochelys coriacea. Dorsal (A) and ventral (B) schematics of a leatherback turtle with the harness used to house the mouth sensor unit. The black lines represent bungee cord in $5 \mathrm{~cm}$ gauge high-density rubber tubing joined on the carapace by a padded aluminium base plate, and at the plastron by a figure-of-eight ring. The mouth sensor unit was attached to the bungee cord inside the tubing of the shoulder strap. Pictures adapted from Pritchard \& Mortimer (1999)

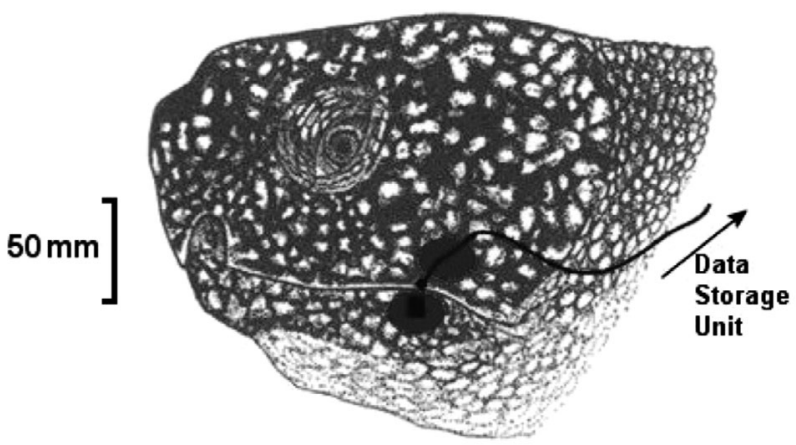

Fig. 3. Dermochelys coriacea. Schematic of leatherback turtle head, showing the positioning of the magnet (lower mandible) and Hall sensor (upper mandible). Picture adapted from Pritchard \& Mortimer (1999). Scale is an approximation based on photographic evidence

face travel, were not classified as dives. The reading before the first measurement below $10 \mathrm{~m}$ was considered to be the beginning of the dive, and the first reading shallower than $10 \mathrm{~m}$ considered to be the end of the dive. All standard deviations relating to percentages were normalized using an arcsine transformation.

All animals (with the exception of 1 turtle instrumented with only a TDR which returned after $38 \mathrm{~d}$ ) returned after a normal internesting interval (mean $10 \mathrm{~d}$, range 8 to $12 \mathrm{~d}$ ). Devices were removed during the subsequent nesting event, with the animals showing no signs of abnormal behaviour and continuing to nest as normal for the duration of the nesting season.

\section{RESULTS}

\section{Internesting diving behaviour}

A total of 8711 dives were recorded over $110.4 \mathrm{~d}$ for 11 turtles, which nested on Levera Beach, Grenada, between 1 May and 6 June 2003. The overall mean (SD) dive depth for all turtles was 54.7 (37.9) $\mathrm{m}$ for a mean (SD) duration of 666 (276) s. Considerable variation was exhibited between individuals with mean dive depths ranging from 23.8 to $100.6 \mathrm{~m}$ for individual turtles. The overall mean surface interval was 420 (762) s (336 [624] s during the night and 522 [894] s during the day). All except one of the turtles returned to Levera Beach within the memory constraints of the TDR $(\sim 15 \mathrm{~d})$. Turtle 8 did not return until $38 \mathrm{~d}$ after nesting. It is not known whether Turtle 8 nested elsewhere during the interim; however, there is no evidence of a nesting event occurring during the $15 \mathrm{~d}$ of recorded diving behaviour.

Broadly speaking the dive profiles could be split into 3 sections: (1) a period whereby dives are consistently 

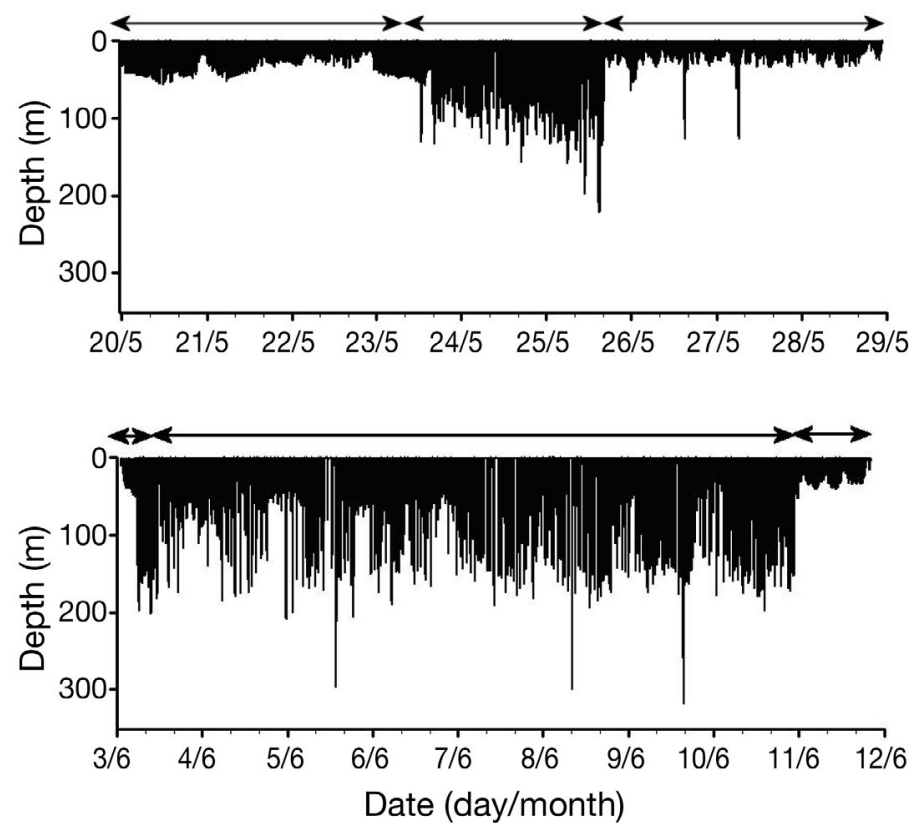

Fig. 4. Dermochelys coriacea. Complete dive profiles from turtle 5 (top) and turtle 9 (bottom). Arrows represent the durations of the 3 sections of the profiles. Periods of shallower diving occurred at the start and end of the internesting, with the 2 phases lasting for 21.5 (22.6) and 20.5 (17.2)\% ( $=10$ turtles) of the entire internesting interval, respectively. The period of deeper diving lasted for $58(25.7) \%$ of the internesting interval ( $\mathrm{n}=10$ turtles)

shallower than average, and vary little in depth; (2) a period of variable dive depths and durations; and (3) a final period similar to the first, with shallow constant diving occurring prior to the nesting events. The duration of these periods was not consistent between turtles. Fig. 4 shows the raw traces from 2 of the turtles (Turtles 5 and 9). For Turtle 5 it can be seen that the middle period is considerable shorter than for Turtle 9, lasting for 3 compared to $7.5 \mathrm{~d}$. For all 10 turtles which returned to nest within the memory capacity of the TDR, the mean (SD) percentages of the internesting interval spent in each of the 3 sections were 21.5 (22.6), 58 (25.7) and 20.5 (17.2)\% for the first shallow, deep and second shallow phases, respectively.

On average, turtles conducted 792 dives during the period of recording, with the average number of dives for each turtle being between 42 and 125 dives $\mathrm{d}^{-1}$. The majority of these dives occurred at the start and end of the internesting period (Fig. 5), with deeper, less-frequent dives occurring during the middle.

Examining the mean percentage of time spent diving per hour for all individuals (Fig. 6), a clear diel cycle becomes apparent, with approximately $12 \%$ more time being spent diving between 18:00 and 06:00 $\mathrm{h}$ than between 06:00 and 18:00 h.

To quantify diel activity during the internesting interval of each turtle a diel index (DI) was created.
Two DI values were created for each day, subtracting the proportion of time spent diving between 21:00 and 03:00 $\mathrm{h}$ from the proportion of time spent diving between 09:00 and 15:00 $\mathrm{h}$ on the preceding and following days (these times being selected to avoid crepuscular activity). Nine of the 11 turtles demonstrated a mean positive DI (with both values from each day being included in this mean), with a greater proportion of time being spent diving at night. Turtle 7 exhibited the most marked overall diel behaviour, with an average of $>36 \%$ more time spent diving during hours of darkness than during daylight. The highest DI for an individual day occurred on 8 May 2003, when Turtle 8 spent $84.8 \%$ of the time between $21: 00$ and $03: 00 \mathrm{~h}$ diving and then only $15 \%$ of the time between 09:00 and 15:00 h the following day diving. Fig. 7 shows a $24 \mathrm{~h}$ dive profile with occasional deep dives occurring during daylight, dives increasing in frequency as dusk approaches and then continual shallow dives during the hours of darkness.

A clear diel cycle, with a tendency to spend more time diving at night to shallower depths, is apparent for the majority of turtles. The only exceptions were Turtle 2, which did not exhibit any pattern, diving for

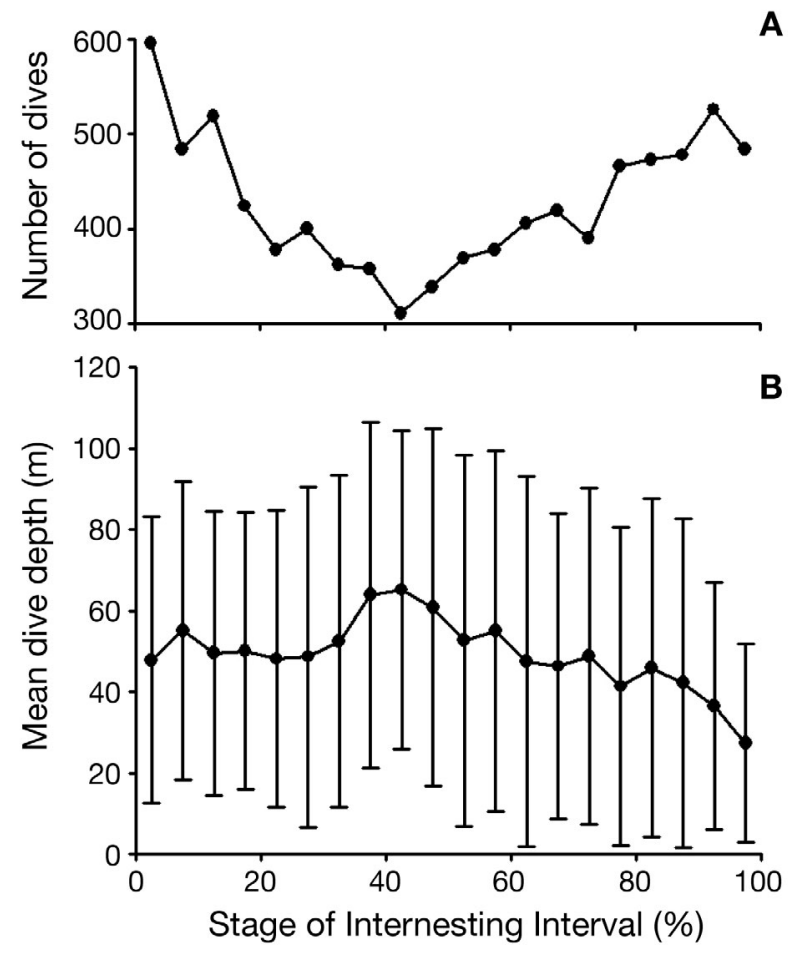

Fig. 5. Total number of dives $(A)$ and mean $( \pm \mathrm{SD})$ dive depth (B) occurring throughout the internesting interval ( $\mathrm{n}=10$ turtles, each conducting a single internesting interval). Mean dive depths showed considerable variation between individuals, but fewer dives occurred during the middle phase of the internesting interval. The latter dives were generally to a greater depth than those conducted at the start and end of the period 


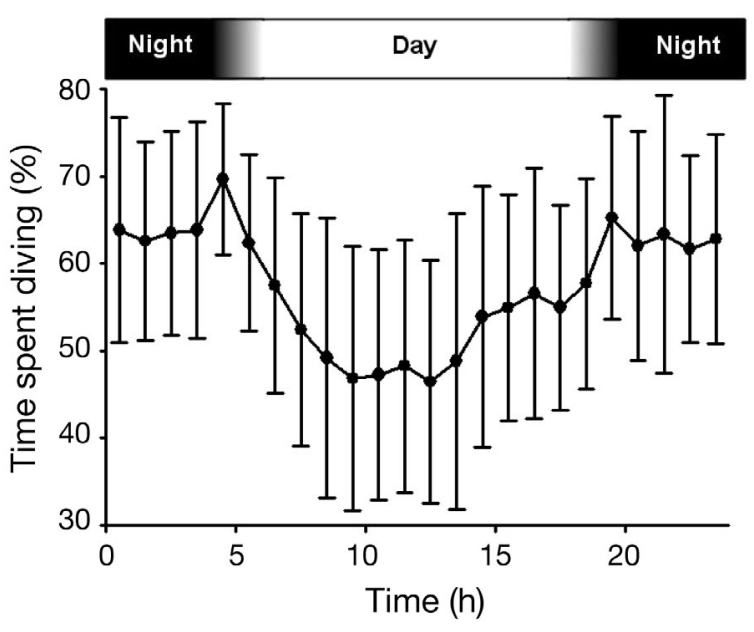

Fig. 6. Mean $( \pm \mathrm{SD})$ percentage of time spent diving in hourly intervals $(\mathrm{n}=11$ turtles), demonstrating the tendency for turtles to spend more time diving during hours of darkness

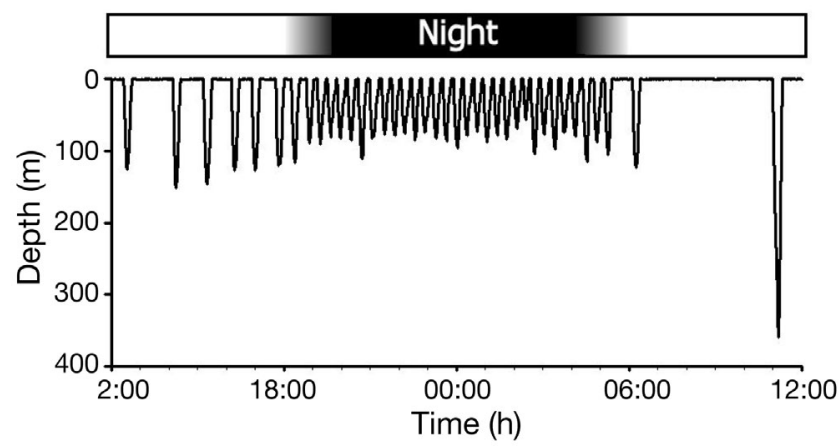

Fig. 7. A 24 h dive profile (Turtle 8) demonstrating occasional deep dives during the day, and repetitive shallower dives at night. This dive pattern was synonymous with foraging on a vertically migrating prey, with deeper prospecting dives occurring during the day and repeated foraging dives at night

45.7 (5)\% of the time during the day (09:00 to 15:00 h) and $52.6(5.4) \%$ at night (21:00 to 03:00 h) (paired $t$-test [mean percentage of time diving per hour], $t=-1.86$, $\mathrm{p}=0.122$ ), and Turtle 11, which uniquely demonstrated diurnal activity. Overall, however, the tendency to spend more time diving between 21:00 and 03:00 $\mathrm{h}$ (mean [SD] 62.9 [11.5]\%) than between 09:00 and 15:00 h (mean [SD] 48.6 [14]\%) was highly significant (paired $t$-test, $t=-6.65, \mathrm{p}<0.0001$ ).

\section{Mouth-opening behaviour}

Unfortunately, 4 of the turtles equipped with IMASENs and TDRs failed to return to the nesting beach, but 1 of these 4 (which was also equipped with a satellite transmitter) was recorded nesting at a near-

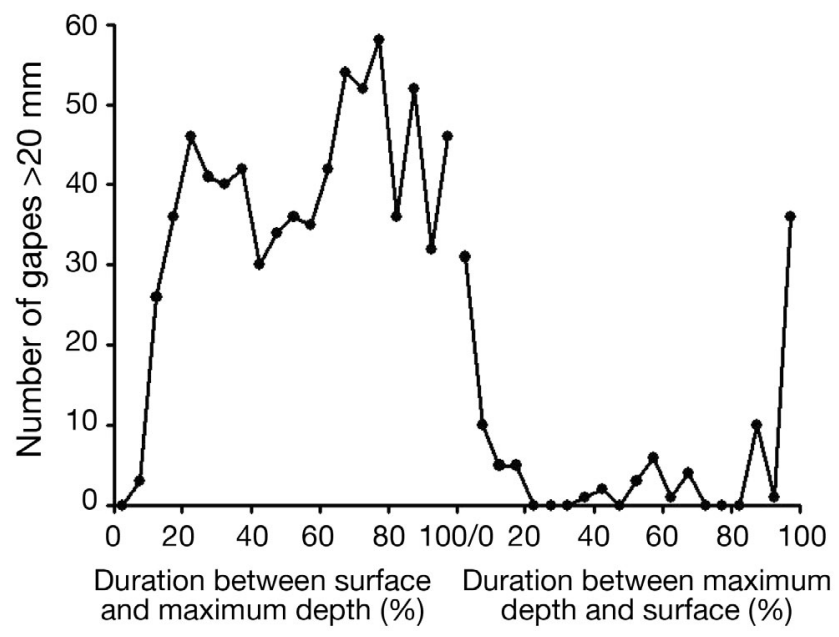

Fig. 8. Distribution of the 856 submerged mouth openings in relation to the stage of the dive from the surface to maximum depth and back to the surface. A total of 741 (86.6\%) of these events took place during the descent, with only $48(5.6 \%)$

occurring between the first and last $5 \%$ of the ascent

by beach before beginning the northerly migration. One of the 2 recovered mouth sensors stopped recording mouth-opening movements after about $10 \mathrm{~min}$ and was not included in this analysis. One unit, however, provided mouth-opening data for a total of 6 h 29 min (from 22:00 h on 4 May 2003).

In total, 46 dives were recorded on the IMASEN to a mean (SD) depth of 51.5 (41) m for a mean duration of 410.7 (287) s. The mean duration between dives was 97.4 (44) s. As this record begins at the start of the internesting interval, many of the dives are likely to be bathymetrically constrained, and sequentially increase in depth and duration as the turtle moves out to deeper water.

During the period recorded, the turtle's mouth opened wider than $20 \mathrm{~mm}$ a total of 856 times. Of these submerged mouth-opening activities, 741 (86.6\%) occurred during the descent (Fig. 8). During the ascent, mouth opening occurred primarily during the initial and final few seconds, with only 48 (5.6\%) mouth-opening activities occurring between the first and last $5 \%$ of the ascent.

A gape $>20 \mathrm{~mm}$ occurred on 36 of the 46 dives. The shallowest mouth-opening event $(12.4 \mathrm{~m})$ during the descent took place during a dive with a maximum depth of $13.8 \mathrm{~m}$. The first mouth-opening event during 24 of the 36 dives took place at a depth of between 15 and $35 \mathrm{~m}$ (Fig. 9). From this point the sensor recorded repeated mouth openings during the descent until the maximum depth was reached or just after the dive ascent began. During the remainder of the ascent, the mouth remained closed until the turtle was very close $(<5 \mathrm{~m})$ to the surface. 


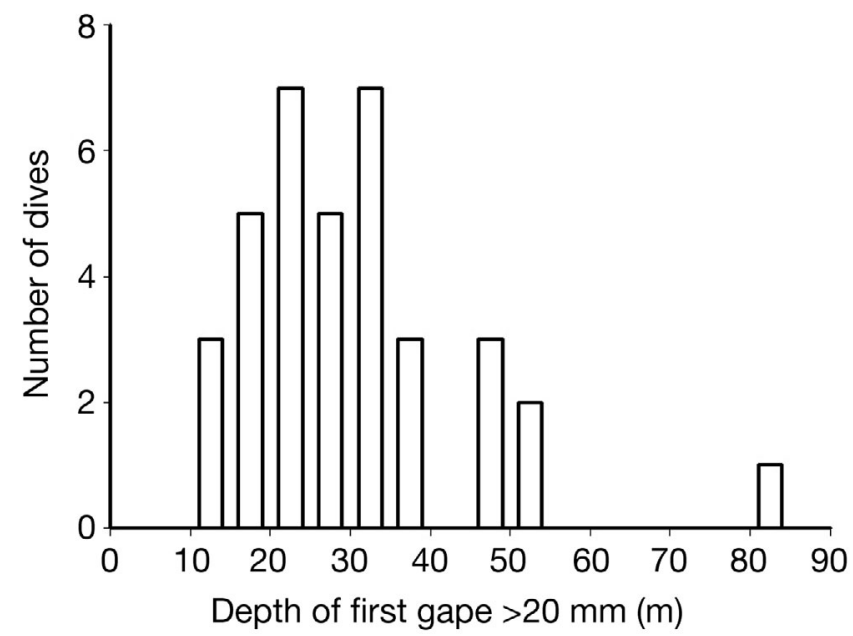

Fig. 9. Frequency histogram showing the depth of the first mouth opening during the 36 dives in which mouth-opening events occurred. In two-thirds of the dives $(n=24)$ the first mouth-opening event occurred between 15 and $35 \mathrm{~m}$

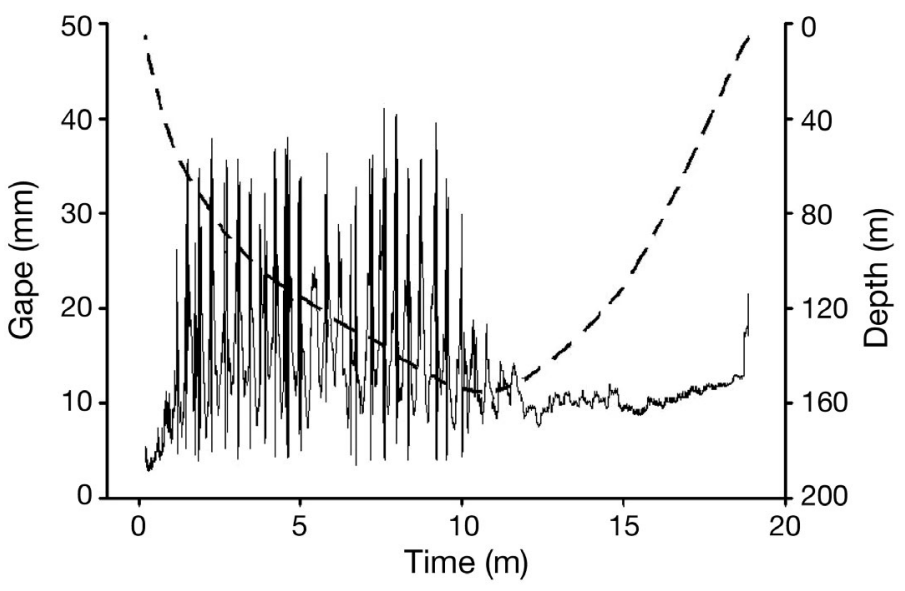

Fig. 10. A typical dive showing depth (dashed line) and mouth-opening activity (solid line), with mouth opening occurring predominantly during the descent

A typical dive (Fig. 10) demonstrates the typical mouth-opening behaviour of a dive occurring during the latter stages of the record. For the first $92 \mathrm{~s}(8 \%)$ of the dive, the mouth does not open wider than $20 \mathrm{~mm}$, then at a depth of $54 \mathrm{~m}$ mouth-opening behaviour becomes more frequent, with an opening event occurring approximately every $20 \mathrm{~s}$ for the next $508 \mathrm{~s}$. These mouth-opening activities are characterised by a series of 3 peaks to a similar gape followed by an interval of approximately $10 \mathrm{~s}$ before the next series of peaks begins. This mouth-opening behaviour ceases $40 \mathrm{~s}$ before the absolute maximum depth of the dive is reached. During the ascent, between the maximum depth and the point $30 \mathrm{~s}$ prior to surfacing, the gape varies very little, ranging between 7.5 and $18.2 \mathrm{~mm}$.

\section{DISCUSSION}

Our current observations confirm and extend previously reported aspects of the diving behaviour, for 2 leatherback turtles equipped with dive computers after nesting on Grenada (Hays et al. 2004). We found for a further 11 individuals that a large proportion of the interesting interval was spent diving, indicating that turtles were active rather than quiescent, and that for 9 of these individuals a clear diel periodicity in diving behaviour was observed with more frequent, shallower diving at night. Initially, when turtles entered the water after nesting, dives were shallow and likewise were shallow for the last day or so of the internesting interval. This pattern presumably reflects shallow bathymetry immediately offshore from the nesting beach, with the turtles swimming offshore and being able to diver deeper during the middle of the internesting interval. To the west of Grenada, deep water is encountered fairly quickly, with depths of 500 and $1000 \mathrm{~m}$ being found approximately 12 and $18 \mathrm{~km}$ northwest of the nesting beach, respectively. Hence the deeper diving we recorded during the middle of the internesting interval is unlikely to have been constrained by bathymetry. This pattern of relatively deep diving is consistent with that previously reported for leatherbacks nesting on islands surrounded by deep water (Eckert et al. 1986), but it contrasts with shallow diving by leatherbacks on sites adjacent to shallow water (Eckert et al. 1996, Southwood et al. 1999).

Leatherbacks are known to sometimes forage on meso-zooplankton, associated with the deep scattering layer, following a diel vertical migration, ascending to shallower depths during hours of darkness (Davenport 1998). Predatory avoidance is considered to be the main driving force behind this migration (see Hays 2003 for review), with meso-zooplankton ascending to forage on surface phytoplankton and micro-zooplankton at night and taking refuge at depth during the day. This theory is backed up by a heightened diel migratory response when predators are present and also by the fact that less-opaque and smaller migrators are generally the first to ascend and the last to descend at dawn and dusk (Hays 2003). Apex predators foraging on species associated with the deep scattering layer can adopt 1 of 3 strategies. Non-air-breathing predators can adjust their depth to correspond to that of their prey, thus maintaining an optimum foraging potential (Nelson et al. 1997). Air-breathing predators are not afforded the benefit of continually tracking the vertically migrating prey, due to the necessity to surface. Air-breathing predators therefore fall into 1 of 2 categories, they are either diurnal foragers, diving deeply to forage on prey during the day (e.g. king penguins; Bost et al. 2002) or nocturnal foragers, waiting until the 
prey has ascended at night, therefore reducing the transport costs associated with reaching prey patches (e.g. fur seals; Horning \& Trillmich 1999). From previous internesting records (Eckert et al. 1989) and during the initial phases of migration (Hays et al. 2004), it has been shown that leatherbacks conduct shallow, frequent dives at night; these dives are assumed to be foraging dives, indicating that leatherbacks exploit prey when they are closest to the surface. Shorter surface intervals during hours of darkness are also indicative of foraging, with the animals minimising surface time in order to maximise foraging time. The variation in the amount of time conducting shallow dives at the beginning and end of the internesting interval may be an indicator of foraging effort (with a longer period of deeper diving in the interim indicating a greater foraging effort). Unfortunately, we only recorded one internesting interval for each turtle and cannot, therefore, state whether this variation is based on the prior experience of the turtle. However, while the pattern of diving we reported is consistent with attempts to forage, overall dives tended to be much shorter than those reported in the Atlantic once turtles leave their breeding sites at the end of the breeding season (Hays et al. 2004). In line with models for optimisation of diving, these observations suggest that while leatherbacks may be attempting to forage during the internesting period, their efforts are met with limited success. For example, we found that dives to $100 \mathrm{~m}$ tended to be around $16.5 \mathrm{~min}$ in duration, which is much shorter than the mean duration of around $25 \mathrm{~min}$ reported for dives to this depth in the Atlantic, suggesting that while leatherbacks may be attempting to forage during this period, their efforts are met with limited success. This is corroborated by the data collected using the mouth sensor, which did not display any irregular mouth openings - which would likely occur if the turtle were manipulating prey. However, mouthopening events did occur when the turtle was submerged, and if these events were not associated with prey manipulation then the question remains as to their purpose. There are several possible explanations for these mouth-opening events, and their true purpose is likely to involve a combination of some, or all, of the following.

Cooling: the nesting event lasts for approximately $2 \mathrm{~h}$; during this time it is likely that the core body temperature of the turtle will increase. The observed mouth-opening events may indicate flushing of the mouth with water, drawing heat from the mucous membranes of the mouth.

Drinking: this is unlikely to be the case in the vast majority of mouth-opening events. A total of 856 mouth-opening events took place during the $6 \mathrm{~h}$ 29 min record presented herein; in contrast, South- wood et al. (2005) recorded a maximum of 27 ingestion events over $3 \mathrm{~d}$ which were attributed to drinking and/or ingestion of prey.

Foraging: on prey small enough to be consumed without extensive manipulation.

Sensing the immediate environment: potentially detecting the presence of predators, environmental cues which could aid navigation and the location of suitable prey fields.

It is also possible that the mouth-opening events are an artefact of experimental design. However, there were no observable differences in mouth-opening behaviour when the sensor was attached to the turtle on the beach, so this seems unlikely. The fact that these mouth-opening events occur predominantly during the descending part of the dive would discount any of device effect, cooling, drinking, foraging on small prey and predator sensing as the primary driving force behind these events. Hays et al. (2003) suggested that green turtles nesting on Ascension Island use airborne cues to navigate when close to the nesting site. It is possible that leatherbacks use similar ocean borne cues to navigate away from the nesting beach into the preferred internesting environment and that these mouthopening events are linked to sensing these cues. Whether the leatherback is utilising sensory organs to navigate or locate prey, it would seem as if the mouthopening events detected during dives are primarily driven by the sensing of chemicals in the water column.

Laboratory experiments have shown that sea turtles have the capability to detect and react to gustatory cues (Manton et al. 1972a,b) by means of organs located in the nasal cavity. Constantino \& Salmon (2003), who presented leatherback post-hatchlings with gelatinous zooplankton homogenates and found that when used in isolation, or in conjunction with visual cues, the introduction of a homogenate elicited a 'biting' response, which may have been misidentified buccal oscillations. As we have shown here, mouthopening activity occurred predominantly on the descending section of dives, with $86.6 \%$ of mouthopening activities occurring during the descent. It is interesting to note that a recent paper (Watwood et al. 2006) examining the echo-locating clicks of sperm whales Physeter macrocephalus revealed that regular clicks associated with long-range prey detection generally occur during the descending section of the dive, beginning at depths $<250 \mathrm{~m}$ on dives which culminated in foraging at depths of approximately $800 \mathrm{~m}$. In most cases, regular clicking ceased as the whales began ascending to the surface. We believe that parallels can be drawn with the activities of the leatherback turtle. It is likely that during the descent leatherbacks are sensing the surrounding water in anticipation of detecting body odours emitted by gelatinous zoo- 
plankton, by moving water across the sensory organs in the nasal cavity. Hochscheid et al. (2005), using the IMASEN, detected buccal oscillations (validated with synchronous video recordings) on captive loggerhead Caretta caretta which increased in frequency when prey were introduced into the tank.

Although the depth of first mouth opening was strongly correlated with maximum depth, it would seem that, as a rule of thumb, turtles begin sensing the surrounding water at a depth of about $30 \mathrm{~m}$ (the dives during which the first mouth-opening event occurred between 25 and $35 \mathrm{~m}$ ranged in maximum depth between 26.83 and $101.3 \mathrm{~m}$ ) and continue until the maximum dive depth is reached. No irregular mouth opening indicative of prey manipulation was noted during any of the dives, and so it remains unknown as to whether leatherbacks forage on the descent or ascent, whether foraging commences as soon as prey is detected, or exactly how leatherbacks manipulate prey. Leatherbacks have been observed feeding on large scyphozoan jellyfish, a process which takes several minutes and involves the animal manipulating the prey at the surface, taking breaths in between prey manipulation and swallowing (James \& Herman 2001). An extended irregular mouth-opening trace would likely betray a foraging event. It would appear, despite no prey being encountered during this $6 \mathrm{~h}$ period after leaving the beach, the turtle was actively attempting to detect prey. It would be unwise to draw any absolute conclusion regarding the foraging behaviour of leatherbacks during the internesting intervals from this study, but we are confident that the data strongly suggests that leatherbacks are attempting to forage. Perhaps more importantly, the proof that this new technology can provide us with vital information regarding the behaviour of free-living leatherback turtles paves the way for future studies with refined attachment techniques allowing longer records to be obtained from more animals.

The poor foraging success during the internesting period could explain the large-scale migratory movements of leatherbacks. A necessity to breed in the tropics presents the turtles with a paucity of suitable prey, so it can be assumed that leatherbacks must begin the breeding season with sufficient reserves to survive it and the subsequent remigration to more prey-replete regions. Successful foraging during the breeding season may dictate the duration of the breeding seasons and therefore the number of successful nesting events. Leatherbacks at more northerly latitudes exhibit larger body masses than those at breeding sites (James et al. 2005), indicating that foraging is considerably more successful in more temperate waters and would be a major driving force behind such large-scale migrations.
Acknowledgements. A.E.M. was supported by a NERC studentship. Further support from NERC was provided by grants to G.C.H. We thank Ocean Spirits Inc. (Grenada), Jon Houghton and many volunteers for help in the field. We are grateful to the Ministry of Agriculture, Forestry, Land and Fisheries in Grenada for permission to conduct fieldwork. We would also like to thank 4 anonymous reviewers for their insightful comments during the preparation of this manuscript.

\section{LITERATURE CITED}

Arnould JPY, Hindell MA (2001) Dive behaviour, foraging locations, and maternal-attendance patterns of Australian fur seals (Arctocephalus pusillus doriferus). Can Zool 79:35-48

Bjorndal KA (1980) Nutrition and grazing behavior of the green turtle Chelonia mydas. Mar Biol 56:147-154

Bost CA, Zorn T, Le Maho Y, Duhamel G (2002) Feeding of diving predators and diel vertical migration of prey: King penguins' diet versus trawl sampling at Kerguelen Islands. Mar Ecol Prog Ser 227:51-61

Brillinger DR, Stewart BS (1998) Elephant seal movements: modelling migration. Can J Stat 20:431-443

Chappell MA, Shoemaker VH, Janes DN, Bucher TL, Maloney SK (1993) Diving behavior during foraging in breeding Adelie penguins. Ecology 74:1204-1215

Constantino MA, Salmon M (2003) Role of chemical and visual cues in food recognition by leatherback posthatchlings (Dermochelys coriacea L). Zoology 106:173-181

Davenport J (1998) Sustaining endothermy on a diet of cold jelly: energetics of the leatherback turtle Dermochelys coriacea. Br Herpetol Soc Bull 62:4-8

Davis L, Boersma P, Court G (1996) Satellite telemetry of the winter migration of Adelie penguins (Pysgoscelis adeliae). Polar Biol 16:221-225

Eckert SA, Nellis DW, Eckert KL, Kooyman GL (1986) Diving patterns of two leatherback sea turtles (Dermochelys coriacea) during internesting intervals at Sandy Point, St. Croix, US Virgin Islands. Herpetologica 42:381-388

Eckert SA, Eckert KL, Ponganis P, Kooyman GL (1989) Diving and foraging behavior of leatherback sea turtles (Dermochelys coriacea). Can J Zool 67:2834-2840

Eckert SA, Liew HC, Eckert KL, Chan EH (1996) Shallow water diving by leatherback turtles in the South China Sea. Chel Conserv Biol 2:237-243

Fedak MA, Arnbom TA, Boyd IL (1996) The relation between the size of southern elephant seal mothers, the growth of their pups and the use of maternal energy, fat and protein during lactation. Physiol Zool 69:887-911

Godley BJ, Richardson S, Broderick AC, Coyne MS, Glen F, Hays GC (2002) Long-term satellite telemetry of the movements and habitat utilisation by green turtles in the Mediterranean. Ecography 25:352-362

Hays GC (2003) A review of the adaptive significance and ecosystem consequences of zooplankton diel vertical migration. Hydrobiologia 163-170

Hays GC, Luschi P, Papi F, del Seppia C, Marsh R (1999) Changes in behaviour during the inter-nesting period and post-nesting migration for Ascension Island green turtles. Mar Ecol Prog Ser 189:263-273

Hays GC, Adams CR, Broderick AC, Godley BJ, Lucas DJ, Metcalfe JD, Prior AA (2000a) The diving behaviour of green turtles at Ascension Island. Anim Behav 59:577-586

Hays GC, Hochscheid S, Broderick AC, Godley BJ, Metcalfe JD (2000b) Diving behaviour of green turtles: dive depth, 
dive duration and activity levels. Mar Ecol Prog Ser 208: 297-298

Hays GC, Glen F, Broderick AC, Godley BJ, Metcalfe JD (2002) Behavioural plasticity in a large marine herbivore: contrasting patterns of depth utilisation between two green turtle (Chelonia mydas) populations. Mar Biol 141:985-990

Hays GC, Akesson S, Broderick AC, Glen F, Godley BJ, Papi F, Luschi P (2003) Island finding ability of marine turtles. Proc R Soc B Suppl Biol Lett 270:S5-S7

Hays GC, Houghton JDR, Isaacs C, King RS, Lloyd C, Lovell P (2004) First records of oceanic dive profiles for leatherback turtles, Dermochelys coriacea, indicate behavioural plasticity associated with long-distance migration. Anim Behav 67:733-743

Hochscheid S, Maffucci F, Bentivegna F, Wilson RP (2005) Gulps, wheezes, and sniffs: how measurement of beak movement in sea turtles can elucidate their behaviour and ecology. J Exp Mar Biol Ecol 316:45-53

Horning M, Trillmich F (1999) Lunar cycles in diel prey migrations exert a stonger effect on the diving of juveniles than adult Galapagos fur seals. Proc R Soc B 266:1127-1132

James MC, Herman TB (2001) Feeding of Dermochelys coriacea on medusae in the northwest Atlantic. Chelonian Cons Biol 4:202-205

James MC, Ottensmeyer CA, Myers RA (2005) Identification of high-use habitat and threats to leatherback sea turtles in northern waters: new directions for conservation. Ecol Lett 8:195-201

Laidre KL, Heide-Jorgensen MP, Dietz R, Hobbs RC, Jorgensen OA (2003) Deep-diving by narwhals Monodon monoceros: differences in foraging behavior between

Editorial responsibility: Rory P. Wilson (Contributing Editor), Swansea, UK wintering areas? Mar Ecol Prog Ser 261:269-281

Manton M, Karr A, Ehrenfield D (1972a) Chemoreception in the migratory sea turtle, Chelonia mydas. Biol Bull (Woods Hole) 143:184

Manton M, Karr A, Ehrenfield D (1972b) An operant method for the study of chemoreception in the green turtle, Chelonia mydas. Brain Behav Evol 5:188-201

Nelson DR, McKibbon JN, Strong WR, Lowe CG, Sisneros JA, Schroeder DM, Lavenberg RJ (1997) An acoustic tracking of a megamouth shark, Megachasma pelagios: a crepuscular diel vertical migrator. Environ Biol Fishes 49:389-399

Ogden JC, Robinson L, Whitlock K, Daganhardt H, Cebula R (1983) Diel foraging patterns in juvenile green turtles (Chelonia-Mydas L.) in St-Croix United-States Virgin Islands. J Exp Mar Biol Ecol 66:199-205

Pritchard PCH, Mortimer JE (1999) Taxonomy, external morphology and species identification. In: Eckert KL, Bjorndal KA, Abrea-Grobois FA, Donnelly M (eds) Research and management techniques for the conservation of sea turtles. IUCN/SSC Marine Turtle Specialist Group Publ. No. 4, Washington, DC

Southwood AL, Andrews RM, Lutcavage ME, Paladino FV, West NH, George RH, Jones DR (1999) Heart rates and diving behaviour of leatherback sea turtles in the eastern Pacific ocean. J Exp Biol 202:1115-1125

Southwood AL, Andrews RD, Paladino FV, Jones DR (2005) Effects of diving and swimming behaviour on body temperatures of Pacific leatherback turtles in tropical seas. Physiol Biochem Zool 78:285-297

Watwood SL, Miller PJO, Johnson M, Madsen PT, Tyack PL (2006) Deep-diving foraging behaviour of sperm whales (Physeter macrocephalus). J Anim Ecol 75:814-825

Submitted: December 19, 2005; Accepted: March 13, 2006 Proofs received from author(s): August 16, 2006 